\title{
Secondary Septicaemia from Intravenous Cannulae
}

\author{
J. H. DARRELL,* M.B., D.C.H., M.C.PATH. ; L. P. GARROD, † M.D., LL.D., F.R.C.P.
}

\begin{abstract}
Cummary : Within a period of only seven months three $\checkmark$ patients in one hospital under treatment with antibiotics by intravenous infusion developed secondary bloodstream infection originating from the site of insertion of the cannula. Two of these infections were fatal. Precautions suggested include strict asepsis, the skin being sterilized with iodine in spirit solution; antibiotic spray ; and changing the cannula site.
\end{abstract}

\section{Introduction}

Though there are advantages of continuous intravenous infusion for long-term antibiotic treatment this method does carry a risk of blood-stream infection via the intravenous cannula site. We describe here three patients developing secondary septicaemia from intravenous cannulae.

\section{Case 1}

This patient was a girl aged 19. A murmur was first heard at the age of 3 years. In 1965 ventricular septal defect was demonstrated by cardiac catheterization. She remained well until March 1968 , when she had a "flu-like" illness, which followed three months after dental fillings. After this, though she felt well, she was noticed to be anaemic and was referred to the outpatient department and admitted to hospital.

On examination her temperature was $102^{\circ} \mathrm{F}$. $\left(38.9^{\circ} \mathrm{C}\right.$.). There was no clubbing or petechiae, but both the liver and the spleen were enlarged. Pansystolic murmur and thrill at the left sternal border and a short mid-diastolic rumble were heard.

Investigations.-Haemoglobin $9 \cdot 3$ g. ; white blood count 12,000 $(90 \%$ polymorphs) ; erythrocyte sedimentation rate $90 \mathrm{~mm}$. in first hour. Streptococcus viridans was isolated from all bottles of three blood cultures taken on admission and from two of three cultures taken the following day.

The patient was treated with benzylpenicillin 20 mega units and streptomycin $1 \mathrm{~g}$. daily by continuous intravenous infusion. Probenecid was also given. Her fever persisted and she developed a generalized skin rash. As the streptococcus was fully sensitive to penicillin (minimum inhibitory concentration $0.06 \mu \mathrm{g} . / \mathrm{ml}$.) streptomycin was stopped. Fever continued until the probenecid was discontinued. One week after starting treatment five blood cultures prepared on two days, one week apart, all remained sterile after two weeks' incubation. Penicillin was stopped after six weeks, but two blood cultures immediately before this yielded Candida albicans and an Achromobacter species, which were also grown from a drip site which had thrombosed shortly before treatment stopped, having been in use for over a week. It was replaced by a new drip at another site, and this episode was not associated with any clinical deterioration. She was treated with amphotericin, $1 \mathrm{~g}$. given over five weeks, which she tolerated well. The question of possible excision of vegetations and closure of the septal defect is to be reviewed; meanwhile she was discharged well.

\section{Case 2}

This patient, a man aged 58, had no history of rheumatic fever, but had been known to have a heart murmur for 30 years, possibly congenital aortic stenosis. $\mathrm{He}$ was admitted to Hammersmith Hospital with a six-weeks' history of fever and muscular pains

* Lecturer, Department of Clinical Bacteriology.

t Honorary Consultant in Chemotherapy.

Royal Postgraduate Medical School, London W.12. following three months after dental treatment. He had previously attended an eye hospital with blurring of vision in the left eye due to embolism of the retinal vessels.

On examination his temperature was $103^{\circ} \mathrm{F} .\left(39 \cdot 4^{\circ} \mathrm{C}\right.$.). There was no clubbing, but a few splinter haemorrhages were found. The spleen was just palpable. Systolic and diastolic murmurs were audible in the aortic area.

Investigations.-Haemoglobin $11.2 \mathrm{~g}$. ; white blood count 13,000 ( $92 \%$ polymorphs) ; erythrocyte sedimentation rate $48 \mathrm{~mm}$. in first hour. Str. viridans was isolated from all bottles of three blood cultures taken on admission.

Benzylpenicillin and streptomycin were given by intravenous infusion. The fever persisted, and cephaloridine $8 \mathrm{~g}$. daily was given in addition to penicillin. A swab of the infusion site one week after treatment was started gave a light growth of coliforms and Pseudomonas aeruginosa. Fifteen blood cultures were prepared after treatment was started. All but two of these were sterile. The two cultures, one 18 days and the other seven weeks after admission, yielded a Candida species from two only of the four bottles of each culture. The patient's clinical condition had improved and the only remaining symptom was a persistent slight fever, but the erythrocyte sedimentation rate remained raised. $\mathrm{He}$ was transferred elsewhere for convalescent management still on the same antibiotic regimen. $\mathrm{He}$ deteriorated, developing abdominal signs, possibly due to mesenteric emboli, a brain-stem lesion, and coagulation defect indicative of defibrination syndrome. He was transferred back to Hammersmith for consideration of urgent valve surgery, but died the following day. Necropsy showed active endocarditis of aortic and mitral valves with yeast-like fungi present.

\section{Case 3}

This patient, a man aged 30 , with sarcoidosis was treated with prednisolone. He developed headaches, associated with intellectual impairment, shown to be associated with cryptococcal meningitis. Treatment was started with amphotericin B through an intravenous drip kept in situ. His condition fluctuated, but after about three weeks' treatment, in spite of a continuing pleocytosis, cryptococci were no longer isolated. Although the course of treatment was not felt adequate to eradicate the meningeal infection, thrombocytopenia meant that urgent consideration had to be given to intrathecal therapy or an alternative antifungal agent. At this point he developed a high swinging fever, reaching $105^{\circ} \mathrm{F}$. $\left(40.6^{\circ} \mathrm{C}\right.$.) associated with painful septic spots on the digits. Staphylococcus aureus was isolated from all bottles of four blood cultures prepared that day, and also in heavy pure culture from the original drip site used for administration of amphotericin, but not from a more recent drip site. Treatment was with methicillin and kanamycin until it was confirmed that the organism was fully sensitive to penicillin, which was used alone in the later stages of treatment. Five subsequent blood cultures were negative, but 13 days after treatment of his septicaemia started he died suddenly of a cardiac arrest.

Necropsy showed the presence of cardiac tamponade, associated with staphylococcal abscesses throughout the myocardium. The cryptococcal infection of the meninges still appeared to be active, and there was microscopical evidence (which culture failed to confirm) of this infection in the vegetations on the aortic valve.

\section{Discussion}

When a long course of antibiotic treatment has to be given, continuous intravenous infusion has two outstanding advantages: an adequate blood level can be continuously maintained, and the patient is spared the pain, and at night the disturbance, of frequent injections. These advantages have to be balanced 
against the danger, illustrated by these three cases, of introducing a fresh infection. How easily the blood stream can be infected via an intravenous cannula site is shown by the report by Plotkin and Austrian (1958) of 40 cases of pseudomonal septicaemia originating in this way, the source being a contaminated solution of Zephiran (benzalkonium chloride) used for " disinfecting" the skin. A similar episode is described by Malizia, Gangarosa, and Goley (1960). Among reports of superinfections similar to those in two of our patients are those of Kay, Bernstein, Feinstein, and Biddle (1961), Prinsloo and Pretorius (1966), and Stanton, Lindesmith, and Meyer (1968). Each of these patients was undergoing treatment for an endocarditis (due respectively to a streptococcus, Staph. aureus, and Escherichia coli), and in each a candidal infection supervened which was attributed to contamination of the blood stream from the site of catheter insertion. In view of such reports Louria (1968) has actually proclaimed the view that intravenous therapy for endocarditis should be avoided so far as possible.

The risk is particularly high during treatment for endocarditis, because the extensive rough surface of existing vegetations greatly facilitates the lodgement of any organism circulating in the blood. The patient under treatment is at the mercy of any organism resistant to the antibiotics administered which can gain access to his blood stream, and every precaution should be taken to prevent such access. Dental extraction during a course of treatment with penicillin and streptomycin for Str. viridans endocarditis was followed by superinfection with another strain of the same organism resistant to both antibiotics, doubtless derived from the mouth, in which resistant strains gain predominance during such treatment (Garrod and Waterworth, 1962).

Apart from its resistance to antibiotics there is no evident reason why $C$. albicans should be the commonest cause of superinfection in endocarditis. How it reaches the skin of the arm or groin is unknown, though its ultimate source is likely to be the mouth. Colonization of the site of insertion of intravenous cannulae by pathogenic organisms appears to be uncommon. With the kind help of Sister D. Z. Cramp, of the cross-infection department, we have obtained cultures from these sites in 31 patients at periods up to 12 days after insertion of the cannula: 14 yielded no growth and the remainder yielded only a few colonies of indifferent organisms such as Staph. albus. All these sites appeared normal, and it is noteworthy that when a fresh infection originates at such a site there are usually signs of phlebitis.

Presumably the risks of intravenous therapy can be diminished by adequate precautions. Clearly the strictest asepsis should be observed in inserting the cannula, the skin having been disinfected with something capable of killing all types of organism: $1 \%$ iodine in $70 \%$ spirit, swabbed off after two minutes with $70 \%$ spirit, is probably the most effective. Apart from covering the site it could possibly be protected from subsequent contamination by further antimicrobic applications. No one wants to encourage the indiscriminate spraying of antibiotic mixtures, but, in view of the observation of McLeod and Taylor (1963) that the contamination of the bladder in paraplegics by catheterization can be prevented by spraying the area of the urethral orifice with such a mixture, similar treatment of intravenous cannula insertion sites would seem justified.

The most important ingredient for this purpose would be nystatin or amphotericin, to guard against candidal infection; a suitable formula, which requires further consideration, should also protect against staphylococci. It may be advisable always to change the site at intervals which we are not in a position to specify. Careful watch should be kept for signs of phlebitis, and the cannula must be removed immediately should they develop. Cultures of both the cannula and a swab taken from the drip site should be prepared, as subsequent attempts to relate blood stream infection to the site may fail. It may even be advisable to tie the vein above the affected area or to excise it. It seems possible that by such precautions as these the risks of intravenous antibiotic medication could be greatly reduced.

An alternative is to abandon the use of a cannula. One unit in this hospital, in view of the secondary infections reported here, now administers antibiotics through small (scalp vein) needles, the site of insertion of which is treated with amphotericin B cream and changed every two days.

We are indebted to our clinical colleagues for permission to refer to patients under their care.

\section{REPERENCES}

Garrod, L. P., and Waterwerth, P. M. (1962). British Heart fournal, 24, 39.

Kay, J. H., Bernstein, S., Feinstein, D., and Biddle, M. (1961). New Engand fournal of Medicine, 264, 907.

Louria, D. B. (1968). Antimicrobial Agents and Chemotherapy, p. 195. McLeod, J. W., and Taylor, M. M. (1963). Scottish Medical fournal, $8,234$.

Malizia, W. F., Gangarosa, E. J., and Goley, A. F. (1960). New England fournal of Medicine, 263, 800 .

Plotkin, S. A., and Austrian, R. (1958). American fournal of Medical Science, 235, 621 .

Prinsloo, J. G., and Pretorious, P. J. (1966). American fournal of

Diseases of Children, 111, 446.
Stanton, R. E., Lindesmith, G. G., and Meyer, B. W. (1968). New England Fournal of Medicine, 279, 737. 